\title{
Região Metropolitana de São Paulo como centro da inovação do Brasil
}

\author{
The Metropolitan Region of São Paulo \\ as an innovation center in Brazil
}

Sandra Lencioni

\section{Resumo}

Aos poucos o conhecimento vem deixando de ser coisa do espírito e se transformando em coisa do dinheiro. As relações sociais relacionadas ao ato de conhecer se submetem, progressivamente, ao capital, e a inovação é vista da perspectiva da troca e do valor. Essa perspectiva orienta a discussão que considera a inovação um recurso do urbano vista a partir da relação entre indústria inovativa e urbano. Isso permite compreender por que a região metropolitana de São Paulo é o centro da inovação no país. Essa condição significa um novo elemento de diferenciação social e territorial do desenvolvimento brasileiro que não pode se traduzir em desigualdade. Diferenças existem, no entanto, não podem se traduzir em desigualdades.

Palavras-chave: conhecimento; inovação; Região Metropolitana de São Paulo.

\begin{abstract}
Little by little, knowledge has ceased to be a thing related to the spirit and has become a thing related to money. The social relations established in the act of knowing have been progressively submitted to capital, and innovation is being viewed from the perspective of exchange and value. Such perspective guides this discussion, which considers innovation an urban resource, viewed from the relationship between the innovative industry and the urban dimension. This enables us to understand why the metropolitan region of São Paulo is the country's innovation center. This condition reveals a new element of social and territorial differentiation of the Brazilian development that should not reinforce inequality. Differences exist and need to be understood; however, they cannot be translated as sources of inequalities.
\end{abstract}

Keywords: knowledge; innovation; Metropolitan Region of São Paulo. 


\section{Introdução}

A inovação não é exclusiva da sociedade contemporânea e, em termo mais geral, nem mesmo o conhecimento, pois esse se constitui como uma faculdade do humano sendo, portanto, inerente ao processo civilizatório. Por meio dessa faculdade, é possível identificar e distinguir objetos, fatos e processos. De maneira geral, conhecer traz a expectativa de poder explicar a natureza, de compreender a ação e de qualificar a intervenção sobre o mundo. Conhecer é saber e se constitui num ato de criação, de descoberta e de invenção. Como criação é potência em ato relativa às artes e à imaginação e, como descoberta, é encontro com aquilo que estava oculto, é achar, é descobrir o que, até então, era desconhecido. Isso significa dizer que descobrir é descortinar, é revelar; por isso, a descoberta só revela o que já existe. Em oposição, a invenção é relativa ao novo, ao que não existe e se relaciona ao ato de conceber, de imaginar e de criar algo ou ideia original que, ainda, não havia sido pensado.

Criar, descobrir e inventar constituem ações do conhecimento humano que são inerentes a todas as sociedades, na medida em que são capacidades do humano. Por isso, estão presentes desde os primórdios da história até os dias atuais, embora nem sempre se apresentem da mesma maneira. Hoje em dia, que é o momento sobre o qual queremos tecer algumas considerações, o conhecimento deixa, cada vez mais, de se constituir como coisa do espírito, para se colocar, de forma bastante absoluta, como coisa do dinheiro.

Melhor é lembrar as palavras esclarecedoras de Jean-François Lyotard que disse:
0 antigo princípio segundo o qual a aquisição do saber é indissolúvel da formação do espírito, e mesmo da pessoa, cai e cairá cada vez mais em desuso. Esta relação entre fornecedores e usuários do conhecimento e o próprio conhecimento tende e tenderá a assumir a forma que os produtores e os consumidores de mercadorias têm com estas últimas, ou seja, a forma valor. 0 saber é e será produzido para ser vendido, e ele é e será consumido para ser valorizado numa nova produção, nos dois casos, para ser trocado. (1986, pp. 4-5)

A forma valor, como Lyotard indica, vem historicamente subjugando o conhecimento e transfigurando-o. Na mesma medida, as relações sociais relacionadas ao ato de conhecer igualmente se submetem ao capital. Portanto, não é de hoje que essa sujeição vem sendo tecida amiúde. Mas, é na contemporaneidade que essa submissão assume tal magnitude e que essa forma subsumida vem se apresentando e se universalizando. Essa captura do conhecimento pelo capital se constitui num exemplo de como a quantidade pode se transformar em qualidade, no sentido da terceira lei da dialética. De como o capital ao submeter progressivamente o conhecimento às suas leis, aprisionando o saber aos imperativos da acumulação, vai deixando no passado a ideia do conhecimento como "coisa do espírito" para se tornar coisa do "dinheiro". Mas, não nos enganemos, embora haja mudança de "coisa do espírito" para "coisa do dinheiro", o conhecimento ainda é conhecimento. Tal como a água que deixa seu estado líquido e se transforma em vapor, se constituindo como força natural capaz de mover as máquinas, o conhecimento capturado pelo capital continua a ser conhecimento, mas sob os desígnios do capital 
ele se apresenta como força social, especificamente como força produtiva.

Amplia-se historicamente o espectro da sujeição ao capital, e o conhecimento é um exemplo desse processo. A subjetividade do conhecer passa, como nunca antes, a ser apropriada pelo capital. Não é à toa e sem sentido que emerge, então, a ideia de que estamos vivendo um momento particular do capitalismo. Tanto é que as características desse momento inspiram nominação nova para a sociedade, a de que estamos vivendo uma sociedade do conhecimento, posto que o conhecimento se constitui como uma potente força social. Em suma, o conhecimento se constitui em um saber subsumido inteiramente ao capital e servindo à sua reprodução.

A inovação, a criação do novo, aparece nessa sociedade do conhecimento fortemente relacionada à criação de um processo ou de um produto, quer seja ele relativo a um bem ou a um serviço. Em ambos os casos, a inovação apresenta-se vigorosamente inserida no circuito de valorização do valor, por isso é que ela é vista da perspectiva da troca e do valor.

Mas, é importante chamar atenção para dois pontos. 0 primeiro, que reitera que a inovação, entendida como algo ou ideia nova, é constitutiva do processo civilizatório. $\mathrm{E}$, 0 segundo de que a relação entre inovação e capital não é nenhuma novidade. 0 que é novo é a forma em que a inovação vem se submetendo ao capital, devido à universalização de sua condição como força produtiva. Sabemos que a invenção da máquina a vapor se constituiu em elemento-chave para a produção industrial e conviveu com um universo de inovações, nem todas elas se apresentando como força produtiva do capital. No entanto, hoje em dia, qualquer ideia inovadora encontra guarida para ser explorada ou para ser examinada como potência para o capital. Qualquer ideia nova levanta, de imediato, a indagação se ela pode ser mercantilizável tornando-se, então, um bom negócio.

A inovação pode ser técnica ou não, como também material ou imaterial. Pode-se inovar, como dissemos, em produto ou em processo, a exemplo das canetas esferográficas surgidas na década de 1930 ou do emprego de robôs na fabricação do automóvel. Pode-se inovar no design de um produto e pode-se inovar imaterialmente, a exemplo das vendas on-line que se realizam num mundo virtual, constitutivo do real. Portanto, a inovação apresenta-se de diversas formas. Muitas até surpreendentes!

Nesse texto reservamos o termo inovação para exprimir a inovação subsumida ao capital. Dissemos subsumida porque esse termo exprime o sentido de estar submetido a algo mais amplo; no caso, a inovação está submetida à reprodução do capital. Trata-se, evidentemente, de uma subsunção real e não apenas formal, pois se dá de forma direta, sem mediações. Conhecimento e inovação serão, então, discutidos como "coisa do capital".

Essa perspectiva orienta a discussão que considera a inovação como um recurso do urbano relacionado à produção industrial. Nesse sentido, tecemos algumas considerações prévias a respeito da íntima relação entre indústria e urbano. Em seguida, discutimos a inovação produtiva e sua relação com o urbano, numa referência que destaca São Paulo como o centro da inovação produtiva da economia capitalista no Brasil. Nas considerações finais defendemos a ideia de que as diferenças de conhecimento podem não ser sinônimo de desigualdade, mas 
as diferenças quanto à inovação podem ser. Embora o capital integre e inove, contraditoriamente ele próprio é fonte de segmentação, de desigualdade e de fragmentação socioespacial.

\section{Inovação produtiva e sua particular relação com o urbano}

Na contemporaneidade, as inovações e o conhecimento capturados pelo capital estão presentes em todas as atividades e em todos os lugares e se constituem em elementos importantes para o avanço das forças produtivas e, consequentemente, para a competição intercapitalista. Quando o conhecimento está subsumido ao capital, coloca-se em pauta a problemática do conhecimento, da cultura em geral, como riqueza patrimonial e a questão da propriedade sobre o que é novo. Dessa condição é que deriva uma multiplicação de normativas sobre patentes, seja no âmbito dos Estados Nacionais, seja no dos organismos supranacionais. Um outro ângulo de reflexão importante é o de que o conhecimento e a inovação quando aglomerados na cidade conformam, por assim dizer, configuram uma nova forma de recurso urbano e suas presenças constituem patrimônio que diferencia as cidades. Uma de suas características é de se aglomerarem em metrópoles reforçando ainda mais a concentração de atividades. São, indubitavelmente, as metrópoles que materializam, de maneira mais exponencial, as condições gerais de produção para que se desenvolva a inovação, nos termos aqui tratados por Lyotard, ou seja, como elemento novo a ser consumido para ser valorizado na produção.
Convém observar que poderíamos falar da relação entre criação e urbano, no sentido da criação como potência em ato relacionada às artes, uma vez que essa tem a capacidade possante de requalificar o urbano. Explorar o trabalho criativo, discuti-lo como trabalho imaterial e relacioná-lo ao uso do território da cidade. Essa abordagem, dentre outras, vem sendo discutida e, de maneira geral, tem sido vista tratada nas discussões sobre cidade criativa. Nossa opção foi a de enfocar a inovação, especificamente, na atividade produtiva, como força produtiva e relacioná-la ao urbano, especificamente vista como um recurso do urbano.

Justificamos esse ponto de vista dada a unidade histórica entre indústria e urbano. Falando sobre essa relação, Henri Lefebvre diz que a industrialização e a urbanização constituem um duplo processo (ou um processo com dois aspectos) "que se revela cada vez mais difícil de ser apreendido, uma vez que a industrialização não produz apenas empresas (os operários e os diretores de empresas), mas sim um conjunto de serviços diversos, centros bancários e financeiros, técnicos e políticos" (Lefebvre, 1973, p. 17). Cabe lembrar que a atividade industrial produziu cidades no início do processo de industrialização, valendo recordar o desenvolvimento de cidades junto às fontes de matérias-primas e energia. Posteriormente, podendo se liberar desses condicionamentos naturais em função da revolução dos transportes, se aglomerou em cidades impulsionando toda sorte de infraestrutura necessária. Uma longa história marca a relação entre indústria e urbano, mas convém apenas sublinhar: a indústria e o urbano constituem uma unidade que se modifica mutualmente pela dinâmica de cada um desses processos, o da industrialização e 
o da urbanização. Se são concordantes em alguns aspectos, se divorciam em outros.

Vamos ter como referência analítica a indústria de transformação, como a de móveis, de aparelhos, de máquinas, de alimentos, de aviões, etc., que pode alcançar grande mobilidade no território. A indústria extrativa não goza dessa liberdade, uma vez que está condicionada aos recursos naturais; ou seja, só pode haver uma indústria extrativa onde há possibilidade de extração de um recurso, a exemplo da indústria extrativa mineral, como a mineração de ferro ou a de cobre. Enquanto essa indústria está aprisionada ao uso que faz do território como recurso natural, a indústria de transformação está condicionada por múltiplos elementos que historicamente são determinados por inúmeros outros aspectos que podem não estar cativos inexoravelmente. Exemplificando, sabemos que produzir palitos de fósforos goza de liberdade de localização que não se encontra na atividade da extração de ouro. Em suma, o que queremos afirmar é que uma das principais características da indústria de transformação é a de buscar a mobilidade territorial para compensar dificuldades que surgem na produção e na concorrência intercapitalista. Por isso, se fazem presentes o abre e fecha de portas de estabelecimentos industriais, o crescimento, a concentração, a desconcentração ou deslocalizações das plantas industriais. Essas dinâmicas fazem parte de sua vida, fazem parte da indústria de transformação tanto quanto a seiva de uma planta.

Se temos um tipo de indústria aprisionado, como a indústria extrativa e um tipo de indústria com grandes possiblidades de mobilidade, como a de transformação, há um terceiro tipo que, em geral, é esquecido na relação com o urbano; talvez, por sua intermitente deslocalização. E o surpreendente é que ela constrói, junto com as infraestruturas, a materialidade fixa do urbano. Estamos a falar da complexa indústria da construção civil. Essa indústria todo mundo conhece, pois, salvo as tendas nos desertos, os iglus e os abrigos assemelhados, em geral as pessoas vivem em casas sobre os terrenos ou sobre as águas. Diferente dos outros dois tipos de indústrias, a indústria da construção não possui um estabelecimento de fabricação fixo, pois cada produto construído apodera-se de um lugar específico; ocupa, por um tempo, o lugar do produto em construção. Em sentido figurado, podemos dizer que essa atividade industrial está em todo lugar, mas em lugar nenhum. Casas e edifícios estão em vários lugares, mas a indústria que os produzem não constitui um lugar fixo como 0 estabelecimento fabril.

Portanto, refletir sobre a relação entre 0 processo de industrialização e o de urbanização requer situar de onde estamos a falar. Como dito, a indústria extrativa está condicionada e aprisionada aos recursos naturais e a da construção civil por descontinuidade da localização da sua produção ocorre em todos os lugares. Embora essas duas indústrias permitam distinguir os lugares, é a indústria de transformação que melhor possibilita analisar a relação entre indústria, urbano e inovação. A relação entre esses três termos propicia compreender meIhor uma faceta do desenvolvimento desigual do território, no caso específico desse texto, do território brasileiro. 


\section{Concentração da inovação na indústria e no urbano. A proeminência da Região Metropolitana de São Paulo}

Em primeiro lugar, cabe esclarecer melhor o que vem a ser inovação quando estamos a falar da atividade industrial. Considera-se que há inovação quando ocorre a criação de um produto ou de um processo novo. Se não inteiramente novo, pelo menos bastante aprimorado. 0 novo pode ser novo para o mercado, mas também é inovação quando é novo apenas para uma empresa, quando ela adota algo que já existe no mercado, mas que no seu âmbito se constitui uma inovação. Por exemplo, se uma empresa adquire uma máquina nova e com isso ela muda sua forma de produzir, trata-se de inovação. Se produz um produto novo, também é inovação e se adota um processo que já existe no mercado, também se trata de inovação. Isso significa dizer que as estatísticas sobre a inovação - que ainda são poucas e apenas estão em fase inicial de seu desenvolvimento - consideram como inovação o produto ou o processo que sejam novos para uma empresa, não precisando ser, necessariamente, um produto ou um processo novo no mundo.

No âmbito da atividade industrial, a inovação não se restringe à produção; ela abrange o setor de serviços e o organizacional e a fronteira entre essas esferas de atividades muitas vezes aparece opaca. Exemplificando, o uso de um software, que embora não tenha sido gerado numa determinada indústria que o está utilizando, por ser uma novidade do processo produtivo dessa, é considerado inovação para essa indústria que o utiliza. Já o design industrial se apenas melhorar o aspecto do produto não é considerado inovação, mas se ele implicar na produção de um produto novo ou de um processo novo, ou mesmo de um processo apenas aprimorado, é considerado inovação. Esses exemplos permitem não só compreender como é vista a inovação, mas também perceber o sentido dos dados sobre inovação na atividade industrial.

A preocupação com o lugar onde está sendo gerada a inovação tem sido objeto de atenção constante dos institutos de pesquisa no Brasil. Todavia, devido ao fato de o tema ser recente, os dados não apresentam série histórica, e a coleta deles, bem como os recortes territoriais não se apresentam homogêneos. Um exemplo claro dessa inconstância é o título da pesquisa feita pelo IBGE - Instituto Brasileiro de Geografia e Estatística. Em 2006, chamava-se Pesquisa de Inovação Tecnológica. Em 2011, Pesquisa de Inovação, a expressar a inovação num sentido mais amplo que o tecnológico, incorporando, portanto, outras facetas da inovação.

Em pesquisa realizada pelo IPEA - Instituto de Pesquisas Econômicas Aplicadas existiam, em 2000, 72 mil empresas com 10 ou mais pessoas ocupadas perfazendo um total de 5.600 .000 trabalhadores. A essas empresas correspondia $92 \%$ do valor adicionado na indústria e examinando-se o número de empresas que haviam feito algum tipo de inovação esse não chegava a $2 \%$ do total (Negri e Salerno, 2005). Um percentual, portanto, muito baixo. Essa pesquisa revelou que foram as grandes empresas que inovaram. Inclusive, elas é que haviam apresentado produtividade maior do trabalho. ${ }^{1} \mathrm{Em}$ outros termos, foram as maiores empresas 
as que mais inovaram e as que apresentaram maior produtividade do trabalho.

Os dispêndios realizados nas atividades inovadoras foram, em 2011, de $\mathrm{R} \$ 50.893 .385$, e a incidência desses dispêndios sobre a receita líquida de vendas correspondeu a 1,6\%. ${ }^{2}$ Cifra, ainda pequena, mas que, ano a ano, se apresenta maior. Interessante é que ao se comparar as empresas nacionais com as estrangeiras, as brasileiras investem $80 \%$ mais em P\&D do que as filiais estrangeiras no Brasil. ${ }^{3}$

Os dados a seguir, produzido pelo IBGE, reúne indústrias transformadoras e extrativas. Portanto, não podem ser diretamente correlacionados aos do IPEA, que considera apenas a indústria de transformação. Considerando-se os 11 primeiros anos do século XXI, houve um crescimento de $45 \%$ no número de empresas inovadoras, o que é bastante ilustrativo. $\mathrm{Ou}$ seja, quase metade das indústrias implementaram algum tipo de inovação.

Da perspectiva da distribuição da atividade industrial inovadora no Brasil, em 2011, 1/3 da indústria inovadora se encontra no território paulista, precisamente, 31,3\%. Seguem a ele, os estados de Minas Gerais (14,1\%), Rio Grande do Sul $(11,2 \%)$, Santa Catarina $(8,6 \%)$ e Paraná $(8,3 \%)$, totalizando, os cinco estados do Brasil, 73,5\%. Isso significa dizer que a indústria inovadora no Brasil se concentra, principalmente, em duas regiões brasileiras, a Sudeste e a Sul (IBGE/Pintec, 2013). ${ }^{4}$

Também, nesses estados é que vamos encontrar as indústrias com maior porcentagem de pesquisadores envolvidos em atividades de P\&D - Pesquisa \& Desenvolvimento. Quase metade deles está no Estado de São Paulo (46,6\%), seguido do Rio Grande do Sul $(11,5 \%)$, de Minas Gerais $(11,1 \%)$, do Rio de Janeiro $(8,3 \%)$, de Santa Catarina $(7,2 \%)$ e do Paraná (6,6\%). 0 conjunto desses estados, todos do sudeste e sul, representa $91,3 \%$ dos pesquisadores envolvidos em atividades de P\&D da indústria brasileira. Ou seja, a quase totalidade de pesquisadores da indústria envolvidos em atividades de P\&D no Brasil se concentra nas regiões Sudeste e Sul, destacando-se o estado de São Paulo (IBGE/Pintec, 2013).

Indústria Inovadora no Brasil - 2000-2011

\begin{tabular}{|c|c|c|c|}
\hline Anos & $\begin{array}{c}\text { Número atual } \\
\text { de indústrias }\end{array}$ & $\begin{array}{c}\text { Número total } \\
\text { de indústrias inovadoras }\end{array}$ & $\begin{array}{c}\text { Taxa de Inovação } \\
(\%)\end{array}$ \\
\hline 2000 & 72.006 & 22.698 & 31,5 \\
2005 & 91.054 & 30.378 & 33,4 \\
2011 & 116.633 & 41.470 & 35,5 \\
\hline
\end{tabular}

Fonte: IBGE (2003, 2008 e 2013). 
Examinando mais acuradamente 0 estado de São Paulo, para o ano de 2005 a mesorregião denominada metropolitana paulista (que engloba além da região metropolitana de São Paulo a microrregião de Santos) e a mesorregião de Campinas (que se aproxima do recorte da região metropolitana de Campinas) concentravam $53,2 \%$ das indústrias inovadoras; precisamente, $49 \%$ na de São Paulo e $12 \%$ na de Campinas (IBGE/Pintec, 2006). ${ }^{5}$

Nesse estado paulista. as empresas que atribuíram alta importância ao desenvolvimento interno de $P \& D$, em 2003, estão nas regiões metropolitanas de São Paulo e Campinas; $27,0 \%$ e $26,2 \%$ respectivamente (Fapesp, 2011). E, considerando-se as ocupações em CT\&I - Ciência, Tecnologia e Inovação - a região metropolitana de São Paulo e a de Campinas concentram $44,7 \%$ e $7,8 \%$ das ocupações, respectivamente. (Fapesp, 2011). ${ }^{6}$

Em suma, a região metropolitana de São Paulo é indubitavelmente o centro da inovação do país, seguida da de Campinas. Se do ponto de vista da importância que as empresas dão ao desenvolvimento interno de $P \& D$, a região metropolitana de São Paulo e a de Campinas são equivalentes, elas são bastante distintas em dois aspectos: a região metropolitana de São Paulo concentra muito mais indústrias inovadoras e pessoal ocupado em CT\&l que a de Campinas. Destaca-se, também, São José dos Campos como importante centro de inovação, dada a existência da indústria aeronáutica e pela presença de várias instituições relacionadas ao setor.

Como observamos anteriormente, uma das características da indústria de transformação é a de ter maior potencial de mobilidade no território. Mas, essa característica se modifica inteiramente quando se trata de uma indústria inovadora. Isso decorre do fato de a indústria inovadora exigir determinadas condições gerais de produção que não são encontradas em todos lugares. Essas condições, a exemplo de centros de pesquisa e universidades se constituem fundamentais para a inovação. $E$, como é sabido, centros de pesquisa e universidades de ponta não são encontradas em todos os lugares. ${ }^{7}$

A indústria inovadora exige determinadas condições gerais de produção. São condições específicas, a exemplo da proximidade com universidades de pesquisa que poderão estabelecer sinergias com ela. E são, também, gerais porque não são condições voltadas para 0 atendimento de uma empresa em particular, mas para um conjunto delas.

Estamos a falar do conceito de condição geral de produção, conceito esse formulado por Marx que guarda relação com o consumo produtivo, ou seja, com o consumo relacionado à reprodução dos meios de produção, como as estradas ou a energia que são consumidas coletivamente.

Daí o termo geral. Não diríamos o mesmo para o consumo de alface numa refeição, que é individual e não serve à produção, mas à alimentação, portanto se situando na esfera da reprodução da força de trabalho.

Para deixar clara a ideia de condição geral de produção, lembremos da energia. Historicamente, a energia era produzida pelo industrial, tendo, posteriormente, sua produção transferida para o Estado, como responsabilidade dele. Ao deixar, portanto, de ser uma condição particular a ser produzida pelo industrial para ser assumida pelo Estado, a energia passou a se constituir como uma 
condição geral de produção. A produção da energia passou a se constituir como um consumo coletivo, interessando a todas as indústrias. Dizendo de outra maneira, a energia passou a ser produzida para atender a todas as indústrias em geral e não a uma em particular e é, nesse sentido, que se transformou numa condição geral de produção.

Convém repetir que as condições gerais de produção estão relacionadas ao consumo coletivo, uma vez que a natureza delas é a de ser consumida coletivamente; ou seja, por mais de uma indústria. No caso que aqui nos interessa, as condições gerais de produção da indústria inovadora não se encontram em todos os lugares, e a presença delas se constitui numa particularidade do território.

As universidades e os institutos de pesquisa constituem condições gerais de produção imprescindíveis à inovação industrial. Não estamos nos referindo a qualquer universidade, mas das de grande porte e intensivas na produção cientifica, como é o caso da USP - Universidade de São Paulo - e da Unicamp - Universidade de Campinas. Também, da Unesp - Universidade Estadual Paulista Júlio de Mesquita Filho. E, de maneira mais específica, do ITA Instituto Tecnológico de Aeronáutica - em São José dos Campos. Por meio desse tipo de universidade e de institutos de pesquisa é que são tecidos laços de cooperação e parcerias com as indústrias inovadoras, bem como é formado pessoal altamente qualificado. Dizendo de outra maneira, a relação entre universidade e empresa no que diz respeito à P\&D se desenvolve de várias maneiras, a exemplo da formação de pessoal altamente qualificado e das parcerias entre universidade e empresa no desenvolvimento de ações e práticas.
A essas condições gerais de produção específicas da inovação industrial se acrescem aquelas necessárias para unir o processo de produção ao de circulação, como as relativas à infraestrutura viária e às demais redes que estruturam o território, como as redes de comunicação e informação. Desenvolve-se, assim, um território que concentra indústrias inovadoras no qual se fazem presentes condições gerais de produção específicas a essa indústria.

Também, o Estado por meio das políticas públicas federais tem incentivado a inovação, por intermédio de vários programas. Grande parte desses concentra-se no Centro Sul do país, como aponta Regina Tunes. Diz que analisando o Sibratec - Sistema Brasileiro de Tecnologia - "é notória a enorme concentração da instalação de redes temáticas de incentivo à inovação no Centro Sul: dos 92 centros instalados no país até 2009, 62 estão concentrados nos estados do Sul e Sudeste brasileiro". Em relação à concessão de crédito a projetos de PD\&I - Pesquisa, Desenvolvimento e Inovação - e à "capacidade tecnológica de médias e grandes empresas, os dados revelam que em 2009 85\% do crédito concedido foi para iniciativas nas regiões Sul e Sudeste". Em relação ao "Programa Inova Brasil... os dados regionalizados revelam que mais de $90 \%$ dos mestres e doutores contratados dentro desse programa trabalham nas regiões Sul e Sudeste" (Tunes, 2014).

Isso significa dizer que como resultado das políticas públicas federais no tocante à inovação tem havido concentração da inovação, particularmente no Sudeste e Sul do país. Mas, um olhar mais agudo vai revelar que é o Estado de São Paulo, precisamente na macrometrópole paulista que se concentra a indústria 
inovadora. Particularmente, na macrometrópole paulista onde cinco regiões metropolitanas figuram: a de São Paulo, a de Campinas, a do Vale do Paraíba, a de Sorocaba e a da Baixada Santista. Esse é o território que se constitui como centro da inovação do país. Em especial, a região metropolitana de São Paulo.

Mencionamos como elementos importantes da concentração da indústria inovadora, a concentração de determinadas condições gerais de produção e as políticas públicas. Mas, cabe destacar um outro aspecto, a importância "das redes de empresas que produzem expertises e conhecimento técnico, concentração de recursos e conhecimento (P\&D) que impulsionam oportunidades para a inovação..." (Feldmann e Florida, 1994, p. 210).

$\mathrm{E}$, como último elemento a destacar, vale lembrar a importância que tem o contato face a face quando a questão envolve uma atividade socialmente criativa, como é a inovação, o que coloca em xeque a ideia de que com o advento da internet teria ocorrido o fim das distâncias que dispensaria o contato face a face. Evidentemente, a internet possibilitu a dispersão da produção, mas não de todas elas.

Se podemos encontrar, por exemplo, em qualquer lugar do estado de São Paulo, energia para a atividade produtiva industrial, não podemos encontrar centros de pesquisa impulsionadores do conhecimento em todos os lugares, nem redes de empresas com expertises e conhecimento técnico. Isso signfica dizer que a tendência é de afirmação de determinados pontos do território com aglomeração de atividades e trabalhadores altamente qualificados voltados para o desenvolvimento da inovação.

A concentração da indústria inovadora no Brasil, em especial na região metropolitana de São Paulo e seu entorno, coloca uma questão de suma importância: o desenvolvimento dessa região como centro inovador em contraponto ao desafio de superar o problema da desiguladade socioespacial do território brasileiro.

\section{Considerações finais. Diferenças não são, necessariamente, desigualdades}

Ao se conformar nessa porção do território paulista uma região de inovação industrial por excelência, se antevê, claramente, que aí reside um novo elemento de diferenciação entre as regiões brasileiras, entre, enfim, os lugares. 0 que essa diferença revela é o fato de que a inovação é exigente de condições específicas para seu desenvolvimento e que essas condições específicas estão aglomeradas territorialmente, sendo uma de suas principais particularidades a de ser pontual, concentrada no território.

A concentrações das condições gerais necessárias à indústria inovadora não se constitui numa particularidade do Brasil; nos países mais avançados os centros de inovação produtiva não se dispersam territorialmente, embora nos ricos países possa haver mais de um aglomerado inovador. Isso porque uma das principais características da inovação industrial é a de ser aglomerativa e concentradora territorialmente.

Como a natureza, que não é igual em todos os lugares, mas diversa, a inovação produtiva caracteriza de forma social e diferente os territórios; pela sua presença, pela 
sua ausência, bem como, e sobretudo, pela sua intensidade. Por isso, de certa forma, a indústria inovadora fragmenta o território, mas isso não quer dizer que essa fragmentação se traduza em ruptura absoluta com o todo e que esse fragmento se constitua numa unidade per se.

Além dessa observação, é importante destacar que a inovação aglomerada no território diferencia os lugares. A diferença, em si, não compromete a coesão territorial e nem se traduz, necessariamente, em desigualdade. Pode se transformar em desigualdade, mas é importante deixar claro que a diferença não é inerente à desigualdade, como se fosse uma consequência natural. Em suma, diferenças existem, mas não são sinônimo de desigualdades. É nesse plano, no da desigualdade e não no da diferença, que se gesta a discriminação.
Diferentes somos, diferentes são os territórios, mas ser desigual não é uma consequência inexorável, ela é antes de tudo, um constructo social. Todo esforço da sociedade deve ser de resistir ao movimento de produção da desigualdade. Todo esforço deve ser feito no sentido de compreender os processos sociais que imprimem diferenças aos territórios, sem que com isso cada característica particular se transfigure numa fragmentação social e territorial e sem que as diferenças do desenvolvimento brasileiro se traduzam em desigualdades.

A concentração da inovação em São Paulo é um elemento a mais a diferenciar a região metropolitana e seu entorno do restante do país. Ela difere e caracteriza São Paulo. 0 desafio que se coloca é o de que tal diferença acentue, ainda mais, as desigualdades sociais e territoriais do país.

\section{Sandra Lencioni}

Universidade de São Paulo, Faculdade de Filosofia, Letras e Ciências Humanas, Departamento de Geografia. São Paulo/SP, Brasil.

slencion@usp.br

\section{Notas}

(1) Enquanto a produtividade do trabalho (calculada segundo a relação entre valor de transformação industrial e pessoal ocupado) é de $74,1 \%$ nas empresas que inovam e diferenciam produtos, ela é de $44,3 \%$ nas empresas especializadas em produtos padronizados e de apenas $10 \%$ nas que não diferenciam produtos e têm produtividade melhor (Negri e Salerno, 2005).

(2) Fonte: IBGE, 2013.

(3) Essa comparação foi feita segundo o mesmo estado da federação, mesmo porte das empresas e com empresas que apresentassem características similares. 
(4) Os dados se referem ao ano de 2006 e têm como base a RAIS - Relação Anual de Informações, Ministério do Trabalho e Emprego.

(5) Como observamos, o universo de dados apresenta-se bastante heterogêneo, inclusive quanto aos recortes territoriais dos dados coletados.

(6) Os dados se referem ao ano de 2006 e têm como base a RAIS - Relação Anual de Informações, Ministério do Trabalho e Emprego.

(7) O conceito de condições gerais de produção tem origem no pensamento de Marx. Ao tratar da maquinaria e da indústria Marx faz algumas observações a respeito dessa ideia, fazendo alguns apontamentos (Marx: [1867] (1984).

\section{Referências}

FAPESP (2011). Indicadores de ciência, tecnologia e inovação em São Paulo: 2010. São Paulo, Fapesp.

FELDMAN, M. P. e FLORIDA, R. (1994). The geographic sources of innovation: technological infrastructure and product innovation in the United States. Annals of Association of American Geographers v. 84, n. 2, pp. 210-229.

FLORIDA, R. L. (2002). The rise of the creative class: and how it's transforming work, leisure, community and everyday life. Nova York, Basic Books.

IBGE (2006). Pesquisa de inovação tecnológica PINTEC: 2005. Rio de Janeiro, IBGE.

(2013). Pesquisa de Inovação: 2011. Rio de Janeiro, IBGE.

LEFEBVRE, H. (1973). Le droit à la ville, suivi de Espace et politique. Paris, Éditions Anthropos.

LENCIONI, S. (2007). Condições gerais de produção: um conceito a ser recuperado para a compreensão das desigualdades de desenvolvimento regional. Scripta Nova. Revista electrónica de geografía y ciencias sociales. Barcelona, Universidad de Barcelona, v. XI, n. 245 (07). Disponível em: http:// www.ub.es/geocrit/sn/sn-24507.htm. Acesso em: 1 ago 2007.

LYOTARD, J-F. (1986). O pós-moderno. Rio de Janeiro, José Olympio.

MARX, K. [1867] (1984). Capítulo XIII. Maquinaria Y Gran Industrial. El Capital. Crítica de la economia política. Tomo I, Libro Primero, v. 2. México, Espanha, Argentina, Colombia, Siglo XXI Ed., pp. 451-614.

NEGRI, J. A. de N. e SALERNO, M. S. (2005). Inovações, padrões tecnológicos e desempenho das firmas industriais brasileiras. Brasília, Ipea.

TUNES, R. (2014). A Territorialização da Indústria Inovadora. XIII SEMINÁRIO DA REDE IBEROAMERICANA DE INVESTIGADORES. Anais. Salvador, 2014. Disponível em: http://www.rii.sei.ba.gov.br/anais/ g5/a\%20territorializacao\%20da\%20industria\%20inovadora\%20no\%20brasil.pdf

VIVANT, E. (2009). Qu' est-ce que la ville créative? Paris, PUF. 